\title{
Missing $\mathrm{OH}$ source in a suburban environ- ment near Beijing : observed and mod- elled $\mathrm{OH}$ and $\mathrm{HO}_{2}$ concentrations in sum- mer 2006
}

\author{
Online supplementary materials
}

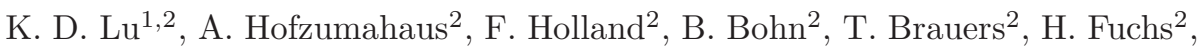

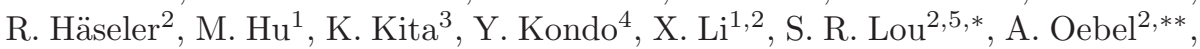
M. Shao ${ }^{1}$, L. M. Zeng ${ }^{1}$, A. Wahner ${ }^{2}$, T. Zhu ${ }^{1}$, Y H. Zhang ${ }^{1}$, F. Rohrer ${ }^{2}$

${ }^{1}$ State Key Joint Laboratory of Environmental Simulation and Pollution Control, College of Environmental Sciences and Engineering, Peking university, Beijing, China

${ }^{2}$ Institut für Energie und Klimaforschung: Troposphäre, Jülich, Germany

${ }^{3}$ Faculty of Science, Lbaraki University, Lbaraki 310-8512, Japan

${ }^{4}$ University of Tokyo, Research Center for Advanced Science and Technology, Tokyo, Japan

${ }^{5}$ School of Environmental Science and Technology, Shanghai Jiaotong University, Shanghai 200240

China

* now at: Shanghai Academy Of Environmental Sciences, Shanghai, China

** now at: AIXTRON SE, Herzogenrath, Germany

To whom correspondence should be addressed.E-mail: f.rohrer@fz-juelich.de; yhzhang@pku.edu.cn. 


\section{This file includes:}

1. $\mathrm{HOx}$ and $k_{\mathrm{OH}}$ measurement results in Sep 2006 (Fig. S1)

2. Averaged diurnal profiles of $\mathrm{O}_{3}, \mathrm{NO}, \mathrm{NO}_{2}, j\left(\mathrm{NO}_{2}\right)$, and VOC speciations for southerly wind days and that of Aug 20 (Fig. S2)

3. Intercomparsions of the modelled HOx concentrations between M0 and RACM-MIM-GK, and that between M5 (MCMv3.2) and MCMv3.1 (Fig. S3, Fig. S4)

4. Retrieved diurnal profiles of X and Y for M1 and M2 (Fig. S5) 


\section{1. $\mathrm{HOx}$ and $k_{\mathrm{OH}}$ measurement results in Sep 2006}

We performed HOx and $k_{\mathrm{OH}}$ measurements during Sep 2006 as well as Aug 2006 (see Fig. S1). In general, similar levels of $\mathrm{OH}$, $\mathrm{HO}_{2}$ and $k_{\mathrm{OH}}$ values and diurnal variabilities were observed for both periods. In this study, the model analysis were limited to the time period in which high precision NO measurement was avaiable. 


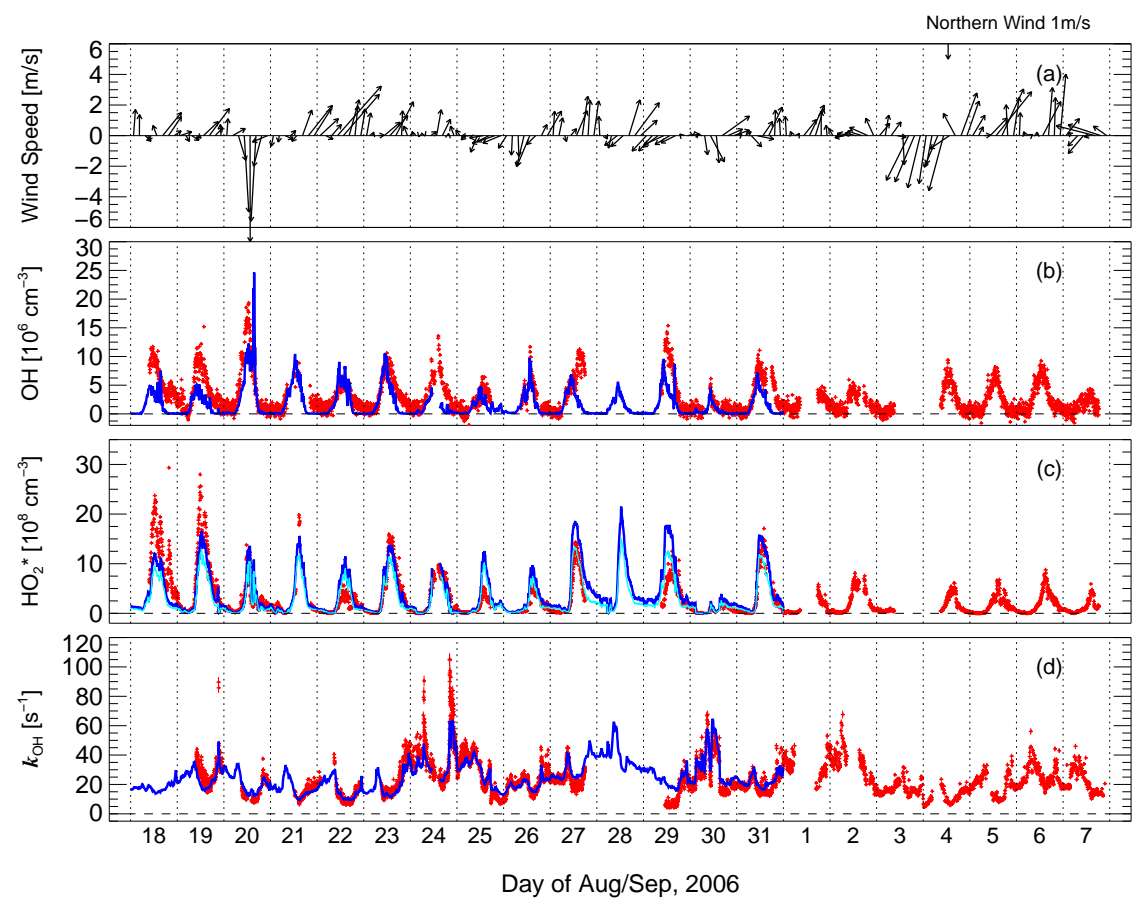

Figure S1. Full time series of the measured (red pluses) and M0 modeled (blue lines) $\mathrm{OH}, \mathrm{HO}_{2}^{*}$ and $\mathrm{k}_{\mathrm{OH}}$ at the Yufa site during CAREBeijing2006 campaign. Cyan line in panel (c) give the modeled $\mathrm{HO}_{2}$. The model results are limited to the existence of the high precision NO data. The wind pattern is given as support information. 
2. Averaged diurnal profiles of $\mathrm{O}_{3}, \mathrm{NO}, \mathrm{NO}_{2}, j\left(\mathrm{NO}_{2}\right)$, and VOC speciations for southerly wind days and that of Aug 20

In Fig. S2, we provide basic photochemical characteristics of the two periods, namely southerly wind days and Aug 20, in discussion of the main paper. For these two periods, similar $j\left(\mathrm{NO}_{2}\right)$ and VOC speciation were observed whereas the major photochemical difference was characterized by the afternoon NOx concentrations. 

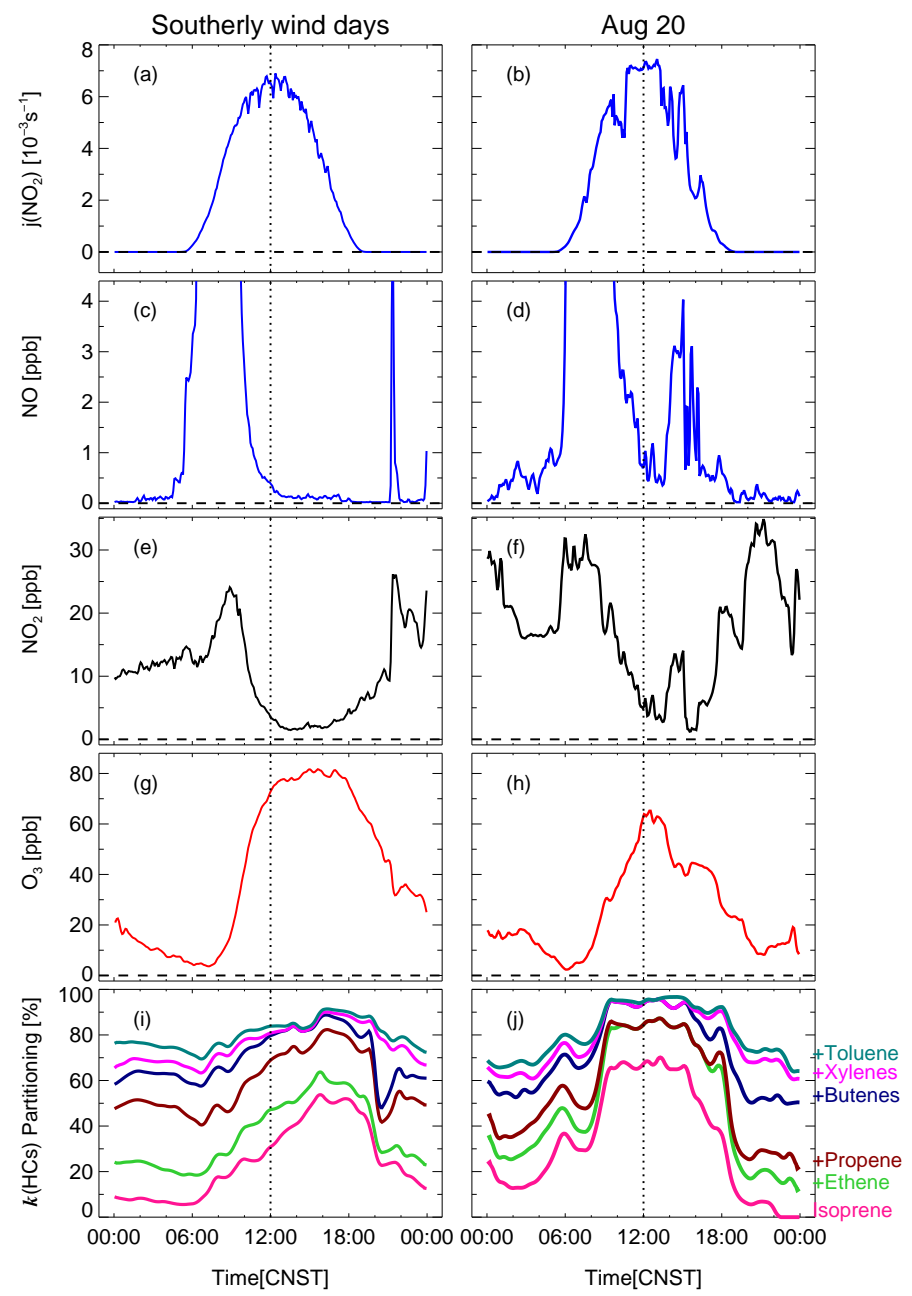

Figure S2. The averaged diurnal profiles of $\mathrm{NO}, \mathrm{NO}_{2}, \mathrm{O}_{3}, j\left(\mathrm{NO}_{2}\right)$ and the speciation of observed $\mathrm{HC}$ reactivities during southerly wind days and that of Aug 20. Butenes=1-Butene, $i$-Butene, trans-2Butene, cis-2-Butene; Xylenes=o-, $m$-, $p$-Xylene. 
3. Intercomparsions of the modelled $\mathrm{HOx}$ concentrations between M0 and model scenario with RACM-MIM-GK, and that between M5 (MCMv3.2) and model scenario with MCMv3.1

By including the $\mathrm{R}(\mathrm{C}=\mathrm{O}) \mathrm{R}^{\prime} \mathrm{O}_{2}+\mathrm{HO}_{2} \rightarrow \mathrm{OH}$ chemistry proposed by Dillon and Crowley (2008); Jenkin et al. (2007) and the isoprene epoxide chemistry (Paulot et al., 2009) into RACM-MIM-GK, we defined the new base case model mechanism, namely M0. Similarly changes were done for MCMv3.1 and thus updated to be MCMv3.2 (see http://mcm.leeds.ac.uk/MCM/project.htt\#New_3.2). As shown by Fig. S3 and Fig. S4, the impact on the modelled HOx concentrations by these two additions is small. For RACM-MIM-GK, the change is less than $1 \%$ for $\mathrm{OH}$ while about $2 \%$ for $\mathrm{HO}_{2}$. For MCMv3.1, the change is about $-2 \%$ for $\mathrm{OH}$ and $2 \%$ for $\mathrm{HO}_{2}$. The reduction of modelled $\mathrm{OH}$ in $\mathrm{MCMv3.2}$ is due to the reduced reaction rate constant of $\mathrm{HO}_{2}+\mathrm{NO}(-4 \%)$ which overcome the enhanced mechanistic $\mathrm{OH}$ recycling. 


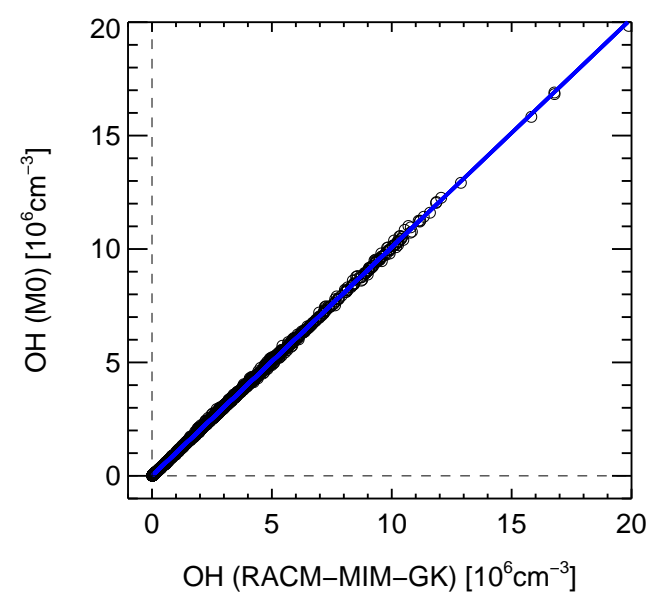

POLY FIT: $Y=a+b^{*} X$

$r=0.9999$

$r^{2}=1.000$

$a=0.002949$

$\sigma(\mathrm{a})=0.00115$

$\mathrm{b}=1.008$

$\sigma(b)=0.000357$

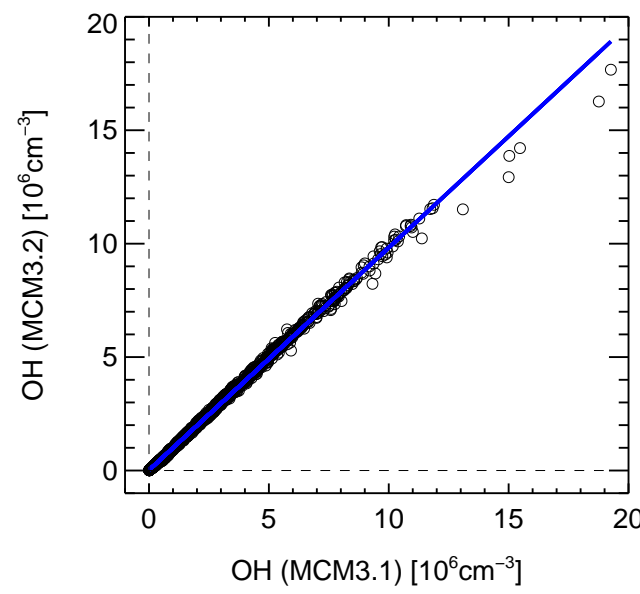

POLY FIT: $Y=a+b^{*} X$

$r=0.9989$

$r^{2}=0.998$

$a=0.01557$

$\sigma(\mathrm{a})=0.00280$

$\mathrm{b}=0.9811$

$\sigma(b)=0.000955$

Figure S3. Regression analysis of the modelled $\mathrm{OH}$ concentrations between M0 and model scenario with RACM-MIM-GK, and those between M5 (MCMv3.2) and model scenario with MCMv3.1. 

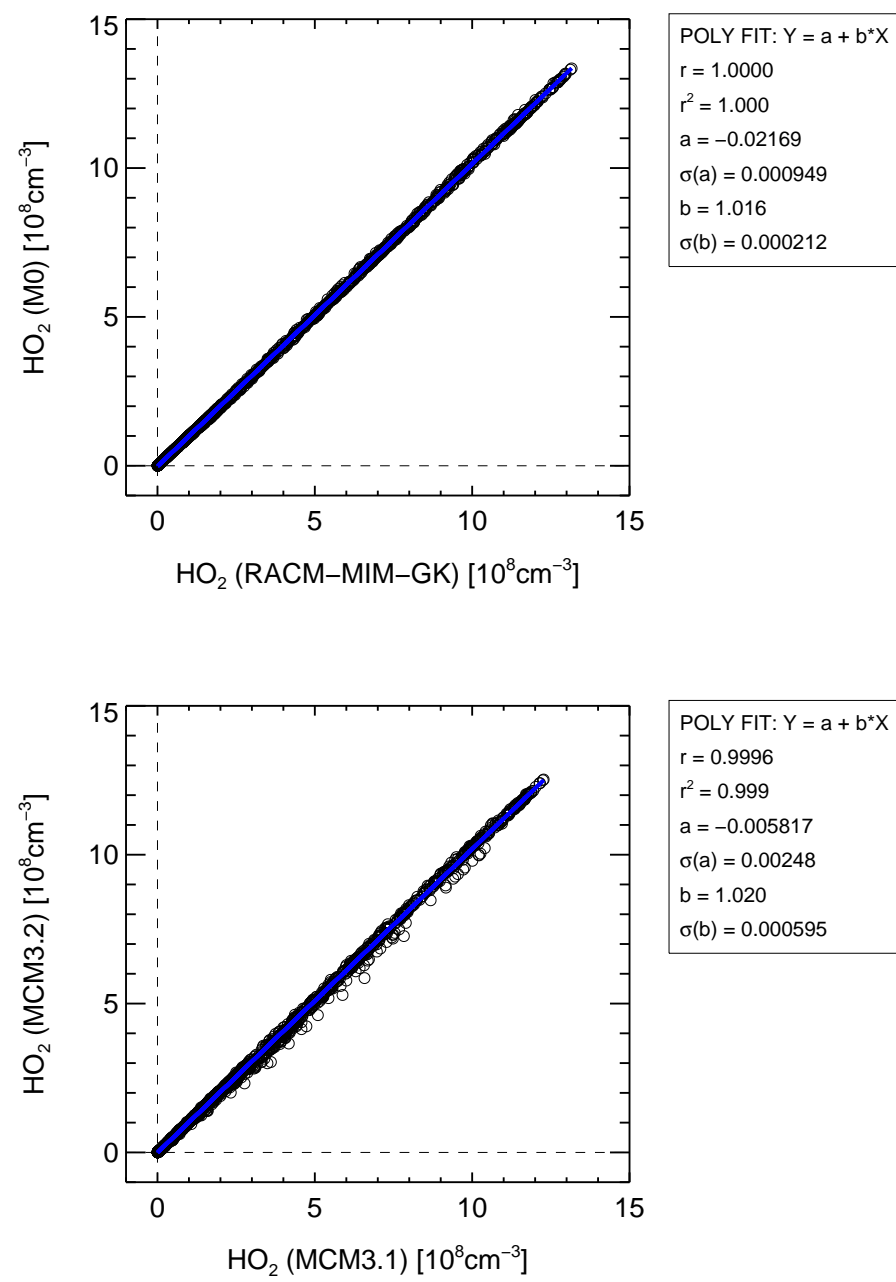

POLY FIT: $Y=a+b^{*} X$

$r=0.9996$

$r^{2}=0.999$

$\mathrm{a}=-0.005817$

$\sigma(a)=0.00248$

$\mathrm{b}=1.020$

$\sigma(b)=0.000595$

Figure S4. Regression analysis of the modelled $\mathrm{HO}_{2}$ concentrations between M0 and model scenario with RACM-MIM-GK, and those between M5 (MCMv3.2) and model scenario with MCMv3.1. 


\section{Retrieved diurnal profiles of $\mathrm{X}$ and $\mathrm{Y}$ for $\mathrm{M} 1$ and $\mathrm{M} 2$}

By taking observed $\mathrm{OH}$ concentrations as the target parameter, the numerically retrieved diurnal profiles of $\mathrm{X}$ and $\mathrm{Y}$ for $\mathrm{M} 1$ and M2, respectively, were shown as Fig. S5. The merit function in this retrieval is set to be

$$
\chi^{2}=\sum_{t=10: 00}^{18: 00}\left(\frac{\mathrm{OH}_{o b s}-\mathrm{OH}_{m o d}}{\sigma\left(\mathrm{OH}_{o b s}\right)}\right)^{2}
$$

of which $\mathrm{OH}_{o b s}$ denote the observed values, the $\mathrm{OH}_{\text {mod }}$ denote the modelled values, $\sigma\left(\mathrm{OH}_{\text {obs }}\right)$ is taken as the measurement accuracy and the time window (10:00 - 18:00) for optimization is selected to match the daytime period when the model-measurement discrepancy of $\mathrm{OH}$ concentrations takes place (cf. Fig $8 \mathrm{a}$ in the main paper). 

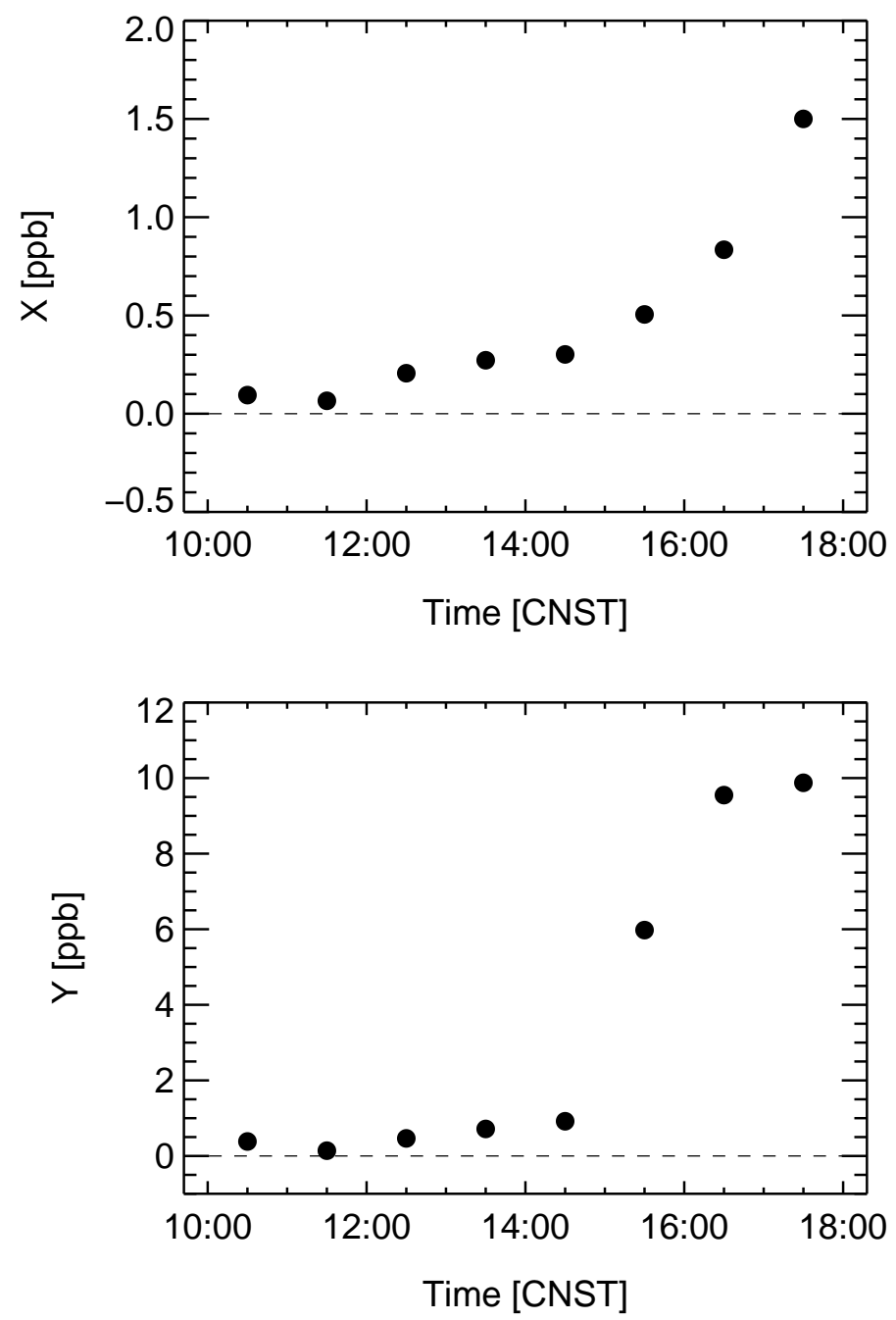

Figure S5. The retrieved diurnal profiles of X and Y for M1 and M2 during 10:00 - 18:00, respectively. 


\section{References}

Dillon, T. J. and Crowley, J. N.: Direct detection of $\mathrm{OH}$ formation in the reactions of $\mathrm{HO}_{2}$ with $\mathrm{CH}_{3} \mathrm{C}(\mathrm{O}) \mathrm{O}_{2}$ and other substituted peroxy radicals, Atmospheric Chemistry and Physics, 8, 48774889, doi:10.5194/acp-8-4877-2008, 2008.

Jenkin, M. E., Hurley, M. D., and Wallington, T. J.: Investigation of the radical product channel of the $\mathrm{CH}_{3} \mathrm{C}(\mathrm{O}) \mathrm{O}_{2}+\mathrm{HO}_{2}$ reaction in the gas phase, Phys. Chem. Chem. Phys., 9, 3149-3162, 2007.

Paulot, F., Crounse, J. D., Kjaergaard, H. G., Kroll, J. H., Seinfeld, J. H., and Wennberg, P. O.: Isoprene photooxidation: new insights into the production of acids and organic nitrates, Atmos. Chem. Phys., 9, 1479-1501, doi:10.5194/acp-9-1479-2009, 2009. 